\title{
Germanium Hydride Radical Trapped During the Photolysis/Thermolysis of Diarylgermylene
}

\author{
Lizhi Tao, Ting Yi Lai, Philip P. Power* and R David Britt* \\ Department of Chemistry, University of California, Davis, California 95616, United States
}

*Corresponding Authors: rdbritt@ucdavis.edu

pppower@ucdavis.edu 


\section{Table of Contents}

Materials and Methods

Supplementary Text: Matlab code for two-point dipole approximation model.

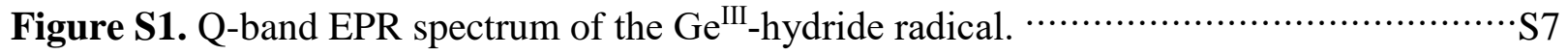

Figure S2. ${ }^{1} \mathrm{H}$ VMT Davies-ENDOR spectra of the Ge ${ }^{\mathrm{III}}$-hydride radical. $\cdots \cdots \cdots \cdots \cdots \cdots \cdots \cdots \cdots \cdots \cdot . \cdot \mathrm{S} 8$

Figure S3. DFT calculations of a Ge ${ }^{\mathrm{III}}$-hydride model with a methyl ligand to $\mathrm{Ge} \mathrm{III}^{\mathrm{III}} \cdot \cdots \cdots \cdots \cdots \cdots \cdot \mathrm{S} 11$

Figure S4. X-band $(15 \mathrm{~K}) \mathrm{CW}$-EPR spectrum of the radical trapped by UV photolysis of

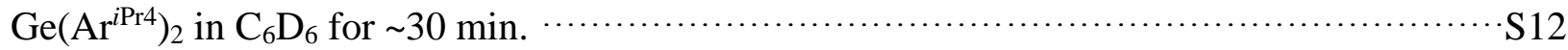

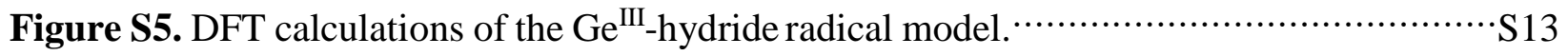

Table S1. EPR parameters for selected mononuclear germanium-centered radicals. ${ }^{\cdots \cdots \cdots \cdots \cdots . . . .56}$

Table S2. The calculated dipolar-component $\mathbf{T}$ of ${ }^{1} \mathrm{H}$-hyperfine tensor by using two-point dipole

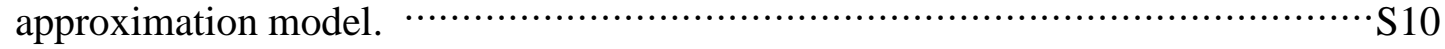

Table S3. Cartesian coordinates of the optimized geometry of the Ge $\mathrm{G}^{\mathrm{III}}$-hydride radical model by presenting a pyramidal geometry for germanium center (shown in Figure S5). $\cdots \cdots \cdot \cdot \mathrm{S} 14$

Table S4. Cartesian coordinates of the geometry of the Ge $\mathrm{GII}^{\mathrm{III}}$-hydride radical model by presenting a planar geometry for germanium center (shown in Figure 4). ……..................S16

Table S5. Cartesian coordinates of the optimized geometry of the Ge $\mathrm{e}^{\mathrm{III}}$-hydride radical model by presenting a pyramidal geometry for germanium center (shown in Figure S3A). $\cdots \cdot$ S18

Table S6. Cartesian coordinates of the geometry of the Ge $\mathrm{GII}^{\mathrm{III}}$-hydride radical model by presenting

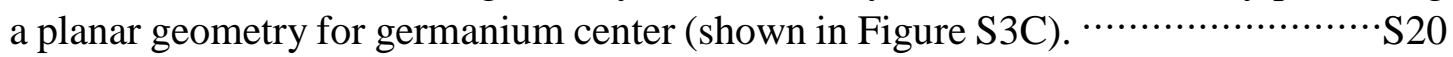




\section{MATERIALS AND METHODS}

Sample preparations. All operations were carried out under anaerobic and anhydrous conditions using modified Schlenk techniques. All solvents were dried over alumina columns and degassed prior to use. Synthesis of $\mathrm{Ge}\left(\mathrm{Ar}^{\mathrm{iPr} 4}\right)_{2}$ and $\mathrm{Ge}\left(\mathrm{Ar}^{\mathrm{iPr} 6}\right)_{2}$ followed the procedures that have been described in Ref 1. A Rayonet-200 photochemical reactor with a wavelength range of $253-570 \mathrm{~nm}$ at approximately $35 \mathrm{~W}$ was used for photolysis reaction. The EPR samples were prepared by UV light exposure at room temperature for $\sim 30 \mathrm{~min}$ in benzene before being flash frozen in liquid nitrogen. The thermolysis treated samples are prepared by heating at $80^{\circ} \mathrm{C}$ for $\sim 30 \mathrm{~min}$ in benzene before being flash frozen in liquid nitrogen.

X-band CW EPR spectroscopy. The X-band (9.38 GHz) continuous-wave (CW) EPR spectra were recorded on a Bruker (Billerica, MA) EleXsys E500 spectrometer which is equipped with a super-high Q resonator (ER4122SHQE). Cryogenic temperatures were achieved and controlled using an ESR900 liquid helium cryostat in conjunction with a temperature controller (Oxford Instruments ITC503) and gas flow controller. CW EPR data were collected under slow-passage, non-saturating conditions at $15 \mathrm{~K}$. The spectrometer settings were as follows: conversion time $=$ $40 \mathrm{~ms}$, modulation amplitude $=0.3 \mathrm{mT}$, and modulation frequency $=100 \mathrm{kHz}$; other settings are given in corresponding figure captions. Spectral simulations were performed using the Easyspin 5.1.10 toolbox ${ }^{2-3}$ within the MatLab software suite (The Mathworks Inc., Natick, MA).

Q-band EPR spectroscopy. Q-band two pulse electron spin-echo (ESE)-detected field swept EPR spectrum ( $\pi / 2-\tau-\pi$ - $\tau$-echo) was collected at $34.220 \mathrm{GHz}$ using a Bruker (Billerica, MA) EleXsys E580 spectrometer equipped with a $10 \mathrm{~W}$ amplifier and a R.A. Isaacson cylindrical TE011 resonator in an Oxford CF935 cryostat. Pulse sequences were programmed with the PulseSPEL programmer via the XEPR interface. Experiment parameters: $10 \mathrm{~K}$, microwave frequency $=34.220$ $\mathrm{GHz}, \pi / 2=12 \mathrm{~ns}$ and $\tau=300 \mathrm{~ns}$.

Q-band pulse ENDOR spectroscopy. Q-band $(\sim 34.0 \mathrm{GHz})$ pulse Davies-ENDOR experiments were performed on a Bruker Biospin EleXsys 580 spectrometer equipped with a $10 \mathrm{~W}$ amplifier and a R.A. Isaacson cylindrical $\mathrm{TE}_{011}$ resonator in an Oxford CF935 cryostat. ENDOR measurements were performed at $10 \mathrm{~K}$ by employing the Davies pulse sequence $(\pi-\mathrm{RF}-\pi / 2-\tau-\pi-\tau-$ echo) for larger hyperfine couplings. ${ }^{4}$ ENDOR spectra were collected stochastically by randomly 
hopping the RF excitation frequency. ${ }^{5}$ Pulse sequences were programmed with the PulseSPEL programmer via the Xepr interface.

For a single molecular orientation with respect to the applied magnetic field, a nucleus $(\mathrm{N})$ with nuclear spin of $I=1 / 2$ (e.g., ${ }^{1} \mathrm{H}$ ) that is hyperfine coupled to an $S=1 / 2$ electron spin will give rise to two ENDOR transitions appearing at positions that are a function of $v_{\mathrm{N}}$, the nuclear Larmor frequency, and $A$, the orientation-dependent hyperfine coupling value. If $v_{\mathrm{N}}>A / 2$, the observed ENDOR transitions are centered at the $v_{\mathrm{N}}$ of the nucleus and split by the hyperfine coupling $A$.

A variable mixing-time (VMT) ENDOR experiment ${ }^{6}$ was conducted to determine the absolute sign of the hyperfine coupling $A$ at a given field position. As shown in Figure S2, the pulse sequence of VMT Davies-ENDOR is $\pi-R F-t_{\text {mix }}-\pi / 2-\tau-\pi-\tau$-echo. Various mixing-times $t_{\text {mix }}$ ranging from $1 \mu$ s to $200 \mu$ s were used and the default delay time for the microwave pulse after RF was $1 \mu$ s for the regular ENDOR experiment. For an $S=1 / 2, I=1 / 2$ spin system, as the mixing time $t_{\text {mix }}$ is increased to a length on the order of the electron-spin relaxation time, the ENDOR response corresponding to $M_{s}=+1 / 2(\alpha)$ electron spin manifold decreases more rapidly than the response corresponding to $M_{s}=-1 / 2(\beta)$ manifold. By comparing the relative intensity of the $v_{+}$ (the high RF frequency peak) and $v_{\text {- }}$ (the low RF frequency peak) ENDOR transitions for the ENDOR spectra acquired at different $t_{\text {mix }}$, we can match each transition to their corresponding electron spin manifold and determine the sign of $A$.

Density functional theory (DFT) computations. All calculations were carried out using the ORCA 4.0.1 quantum chemistry program. ${ }^{7}$ Unrestricted Kohn-Sham geometry optimizations were carried out using BP86 density functional ${ }^{8-9}$ along with the zero-order regular approximation (ZORA) to include the scalar relativistic effects. ${ }^{10-12}$ The ZORA-def2-TZVP basis sets were used for the heavier atom, Ge, while the basis set of SVP was used for light atoms (hydrogen and carbon). The calculations were sped up by employing the resolution of identity (RI) approximation along with the segmented all-electron relativistically contracted (SARC/J) coulomb-fitting auxiliary basis set which is implemented in ORCA 4.0.1. ${ }^{13-14}$ Increased integration grids (Grid5) and tight SCF convergence were used throughout the calculations. Solvent effects have been taken into account with conductor-like screening model (COSMO) with a dielectric constant $\varepsilon$ of 2.3 for benzene..$^{15-17}$ 
EPR parameters for $\mathrm{Ge}^{\mathrm{III}}$-hydride model were calculated by using Unrestricted Kohn-Sham (UKS) formalism and employing the hybrid meta-GGA TPSSh wave functional. ${ }^{18}$ The ZORAdef2-TZVP basis set was used for Ge, while the basis set of EPR-II was used for C and H. The calculations were sped up by employing the resolution of identity (RI) approximation along with the segmented all-electron relativistically contracted (SARC/J) coulomb-fitting auxiliary basis set. ${ }^{13-14}$ Increased integration grids (Grid5) and tight SCF convergence were used throughout the calculations. 
Table S1. EPR Parameters for Selected Mononuclear Germanium-centered Radicals.

\begin{tabular}{|c|c|c|c|c|c|}
\hline \multirow{2}{*}{ Radical } & \multirow{2}{*}{$\begin{array}{l}g \text {-values }= \\
{\left[g_{1}, g_{2}, g_{3}\right]}\end{array}$} & \multirow{2}{*}{$g_{\text {iso }}{ }^{a}$} & \multicolumn{2}{|c|}{$a_{\text {iso }}{ }^{73} \mathrm{Ge}$} & \multirow{2}{*}{ Ref. } \\
\hline & & & $\mathbf{m T}$ & MHz & \\
\hline$\cdot \mathrm{GeH}_{3}$ & {$[2.017,2.017,2.003]$} & 2.012 & 7.5 & 211 & $19-20$ \\
\hline$\cdot \mathrm{GeMe}_{3}$ & - & 2.010 & 8.47 & 238 & 21 \\
\hline$\cdot \mathrm{GePh}_{3}$ & {$[2.009,2.007,2.001]$} & 2.005 & $-8.4^{\mathrm{e}}$ & $-236^{\mathrm{e}}$ & 22 \\
\hline$\cdot \mathrm{Ge}\left[\mathrm{CH}\left(\mathrm{SiMe}_{3}\right)_{2}\right]_{3}$ & - & 2.0078 & 9.2 & 258 & 23 \\
\hline$\cdot \mathrm{Ge}\left[\mathrm{N}\left(\mathrm{SiMe}_{3}\right)_{2}\right]_{3}$ & - & 1.999 & 17.1 & 478 & 23 \\
\hline$\cdot \mathrm{Ge}\left(\mathrm{SiMeBu}_{2}^{\mathrm{t}}\right)_{3}$ & & 2.0229 & 2.0 & 56 & 24 \\
\hline$\left\{: \mathrm{Ge}\left[\mathrm{CH}\left(\mathrm{SiMe}_{3}\right)_{2}\right]_{2}\right\}^{\cdot-}$ & - & 2.0125 & 1.25 & 35 & 25 \\
\hline Cy-cAAC: $\mathrm{GeN}\left(\mathrm{SiMe}_{3}\right) \mathrm{Dip}^{\mathrm{b}}$ & {$[2.016,2.004,1.9975]$} & 2.003 & \multicolumn{2}{|c|}{-} & 26 \\
\hline Me-cAAC: $\mathrm{GeN}\left(\mathrm{SiPh}_{3}\right) \mathrm{Mes}^{\mathrm{b}}$ & {$[2.018,2.004,1.995]$} & 2.005 & \multicolumn{2}{|c|}{-} & 26 \\
\hline neutral Ge(I) radical ${ }^{c}$ & {$[2.001,1.997,1.968]$} & 1.988 & \multicolumn{2}{|c|}{ 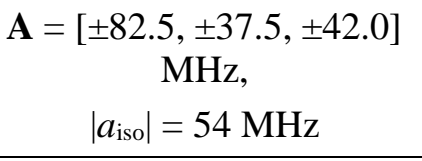 } & 27 \\
\hline $\mathrm{Ge}^{\mathrm{III}}$-hydride ${ }^{\mathrm{d}}$ & {$[2.029,2.003,1.990]$} & 2.007 & \multicolumn{2}{|c|}{$\begin{array}{c}\mathbf{A}=[-10,-90,-10] \mathrm{MHz}, \\
a_{\text {iso }}=-37 \mathrm{MHz}\end{array}$} & $\begin{array}{c}\text { this } \\
\text { work }\end{array}$ \\
\hline
\end{tabular}

${ }^{\mathrm{a}} g_{\text {iso }}{ }^{2}=\left(g_{1}^{2}+g_{2}^{2}+g_{3}^{2}\right) / 3$.

${ }^{\mathrm{b}} \mathrm{cAAC}=$ cyclic alkyl(amino) carbenes.

${ }^{\mathrm{c}}\left[\left({ }^{\mathrm{Bu}}{ }^{\mathrm{N}} \mathrm{Nacnac}\right) \mathrm{Ge}:\right]^{\cdot}$, where ${ }^{\mathrm{Bu}}{ }^{t} \mathrm{Nacnac}=\left\{\left[\mathrm{N}(\mathrm{Dip}) \mathrm{C}\left(\mathrm{Bu}^{\mathrm{t}}\right)\right]_{2} \mathrm{CH}\right\}^{-}$, Dip $=\mathrm{C}_{6} \mathrm{H}_{3} \mathrm{Pr}^{\mathrm{i}}{ }_{2}-2,6$.

${ }^{\mathrm{d}} g$ values from both X-band and Q-band EPR; $A$ values from X-band EPR. This radical is retained upon warming up to room temperature and re-cooled down to cryo-temperature.

${ }^{\text {e}}$ The sign of the hyperfine is determined, with the others undetermined. 


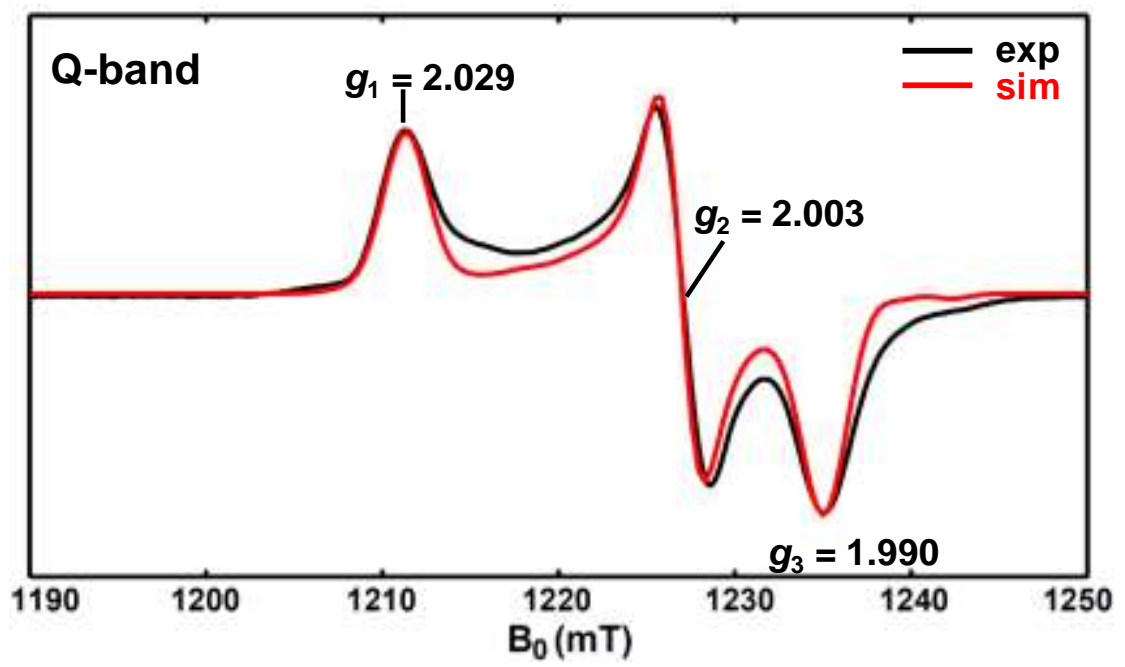

Figure S1. Q-band (34.22 GHz) pseudo-modulated electron spin-echo detected field-swept EPR spectrum of the radical trapped by UV photolysis of $\mathrm{Ge}\left(\mathrm{Ar}^{i \mathrm{Pr} 4}\right)_{2}$ in benzene for $\sim 30 \mathrm{~min}$, with the corresponding X-band CW-EPR spectrum shown in Figure 1. The ${ }^{1} \mathrm{H}$-hyperfine splitting is masked by greater effects of $g$-anisotropy in the higher microwave-frequency/magnetic field Q-band EPR spectrum. The simulation (red trace) parameters are as follows: $g=[2.029,2.003,1.990], A^{73} \mathrm{Ge}=$ $[-10,-90,-10] \mathrm{MHz}(7.8 \%$ abundance $), A^{1} \mathrm{H}=[-23.0,-20.5,-31.5] \mathrm{MHz}$. The parameters are taken from X-band EPR and ENDOR simulations. 


\section{The absolute sign of ${ }^{1} \mathrm{H}_{\text {hydride }}$}

The absolute sign is determined via variable mixing-time (VMT) ENDOR experiment ${ }^{6}$ by recording ENDOR spectra at the magnetic field (1223.7 mT) corresponding to $g_{2} 2.003$, as shown in Figure $S 2$. As the mixing time $t_{\text {mix }}$ is increased from $1 \mu$ s (black trace) to $200 \mu$ s (red trace), the high RF frequency peak $\left(v_{+}=\left|v_{\mathrm{N}}-M_{s} A\right|\right)$ of ${ }^{1} \mathrm{H}$ decreases, suggesting that the $v_{+}$ENDOR transition corresponds to the $\alpha$ electron spin manifold $\left(M_{s}=+1 / 2\right)$, giving a negative hyperfine coupling $A$.

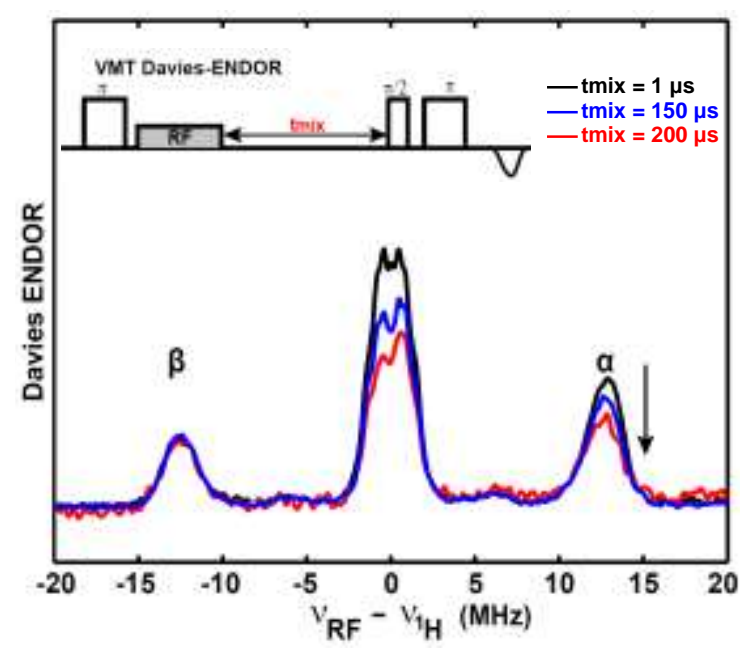

Figure S2. ${ }^{1} \mathrm{H}$ VMT Davies-ENDOR spectra of the radical trapped as a result of UV photolysis of $\mathrm{Ge}\left(\mathrm{Ar}^{\mathrm{iPr} 4}\right)_{2}$ in benzene for $\sim 30 \mathrm{~min}$ recorded at magnetic field of $1223.7 \mathrm{mT}(\mathrm{g}=2.003)$ and $\mathrm{T}$ $=10 \mathrm{~K}$, acquired by using various $t_{\text {mix }}$. The ENDOR transitions corresponding to $\beta$ electron spin manifold $\left(M_{s}=-1 / 2\right)$ are normalized, with the decrease in the ENDOR transitions corresponding to $\alpha$ spin manifold $\left(M_{s}=+1 / 2\right)$. Other spectrometer settings are microwave frequency $=34.30 \mathrm{GHz}$, microwave inversion pulse $\pi=80 \mathrm{~ns}, \pi / 2=12 \mathrm{~ns}, \tau=300 \mathrm{~ns}$ and RF pulse $=20 \mu \mathrm{s}$. 


\section{Matlab code for two-point dipole approximation model}

$\%$ displaced point dipole for $1 \mathrm{H}$ with $\mathrm{p}$ orbital treating as two points

clear all;

$\mathrm{TH}=@(\mathrm{r})$ gfree*nucgval('1H')*bmagn*nmagn*1e-7/planck/((r/1e9)^3);

rho $=0.80 ; \%$ population of $\mathrm{Ge} 4 \mathrm{p}$ orbital

disp $=1.45 ; \%$ displacement of $4 p$ lobes in angstroms

$\%$ coordinates of up and down lobes of pi orbitals

$\mathrm{Geu}=\left[\begin{array}{lll}0 & 0 & \text { disp }\end{array} .^{\prime} ;\right.$

Ged $=\left[\begin{array}{lll}0 & 0 & \text {-disp }\end{array}\right.$. ;

Genode $=\left[\begin{array}{lll}0 & 0 & 0\end{array}\right] . ;$

$\mathrm{PDBZ}=[0 ; 0 ; 1] ; \%$ reference axis for rotation matrix

$\%$ population of $\mathrm{p}$ orbital

p1 $=[0.5,0.5,0] .{ }^{\prime} ; \%$ divided into three fragments [lobe lobe node];

proj $=$ rho*p1;

$\mathrm{j}=1$;

$\mathrm{rGeH}=1.57 ; \% \mathrm{Ge}---\mathrm{H}$ internuclear distance in angstroms

theta $=0 *$ pi $/ 180 ; \%$ angle between $\mathrm{Ge}---\mathrm{H}$ vector and $4 \mathrm{p}$ orbital node plane

NucPos $=\left[0, \mathrm{rGeH}^{*} \cos (\right.$ theta $), \mathrm{rGeH}^{*} \sin ($ theta $\left.)\right] . ;$ \% coordinates of hyperfine coupled nucleus in

3-D space

$\%$ vectors between nucleus and lobes of pi orbitals in PDB frame

$\mathrm{GeHu}=(\mathrm{NucPos}-\mathrm{Geu})$;

GeHd = (NucPos-Ged);

GeHnode $=($ NucPos-Genode $)$;

$\mathrm{ZC}=[\mathrm{GeHu}$ GeHd GeHnode $] ;$

Anet1 $=0$; \%initialize Anet

for $\mathrm{i}=1: 3$;

$\mathrm{rA}=\mathrm{ZC}(:, \mathrm{i})$;

$\mathrm{zA}=\mathrm{rA} /$ norm $(\mathrm{rA})$

$\mathrm{yA}=\operatorname{cross}(\mathrm{zA}, \mathrm{PDBZ}) ; \mathrm{yA}=\mathrm{yA} / \operatorname{norm}(\mathrm{yA})$;

$\mathrm{xA}=\operatorname{cross}(\mathrm{yA}, \mathrm{zA}) ; \mathrm{xA}=\mathrm{xA} / \operatorname{norm}(\mathrm{xA})$;

$\mathrm{R} \_\mathrm{A}=[\mathrm{xA}$ yA zA];

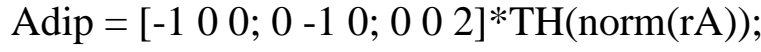

Aint $=\mathrm{R} \_$A*Adip*R_A.'; \% transform point-dipole frame into PDB frame

Anet $1=(\operatorname{proj}(\mathrm{i}) *$ Aint $)+$ Anet $1 ; \%$ weight intrinsic $A_{\text {dip }}$ by projection factor and add to total effective anisotropic hyperfine

end

$[\mathrm{R} 1, \mathrm{~A} 1]=\operatorname{eig}\left(\right.$ Anet1); \% diagonalization of the summed $A_{\text {dip }}$ matrix $\operatorname{sort}(\operatorname{diag}(\mathrm{A} 1))$ 


\section{The out-of-plane angle $\theta$}

By using the two-point dipole approximation model (the above Matlab code), the corresponding dipolar-component tensor $\mathbf{T}_{\text {cal }}$ can be obtained by varying the out-of-plane angle $\theta$. As shown in Table S2, the $\mathbf{T}_{\text {cal }}$ for the hydrides are very sensitive to the out-plane-angle $\theta$. $\mathbf{T}_{\text {cal }}$ is close to the experimental tensor when $\theta$ is in the range of $0 \sim 5^{\circ}$, suggesting the Ge $\mathrm{e}^{\mathrm{III}}$-hydride radical we trapped is in a pseudo-planar geometry.

Table S2. The calculated dipolar-component $\mathbf{T}$ of ${ }^{1} \mathrm{H}$-hyperfine tensor for the hydride with varying out-of-plane angle $\theta$ by using the above two-point dipole approximation model.

\begin{tabular}{c|c}
\hline Out-of-plane angle $(\theta)$ & T $(\mathrm{MHz})$ \\
\hline $0^{\circ}$ & {$[2.47,4.01,-6.48]$} \\
\hline $1^{\circ}$ & {$[2.43,4.05,-6.48]$} \\
\hline $2^{\circ}$ & {$[2.32,4.17,-6.49]$} \\
\hline $3^{\circ}$ & {$[2.17,4.34,-6.51]$} \\
\hline $4^{\circ}$ & {$[1.99,4.55,-6.54]$} \\
\hline $5^{\circ}$ & {$[1.79,4.78,-6.57]$} \\
\hline $6^{\circ}$ & {$[1.57,5.04,-6.61]$} \\
\hline $7^{\circ}$ & {$[1.36,5.30,-6.66]$} \\
\hline $8^{\circ}$ & {$[1.14,5.58,-6.72]$} \\
\hline $9^{\circ}$ & {$[5.88,0.90,-6.78]$} \\
\hline $10^{\circ}$ & {$[6.18,0.67,-6.85]$} \\
\hline $\exp ^{\circ}$ & {$[2.0,4.5,-6.5]$} \\
\hline
\end{tabular}


B

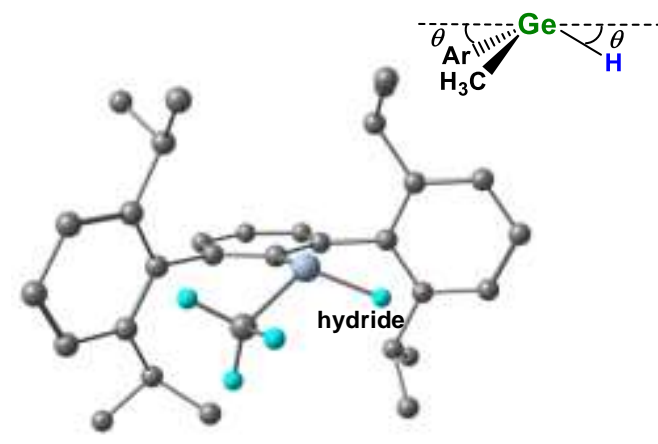

\begin{tabular}{|c|c|c|c|}
\hline & $\begin{array}{c}\text { out-of-plane } \\
\text { angle }(\theta)\end{array}$ & $A^{73} \mathrm{Ge}, \mathrm{MHz}$ & $A^{1} \mathrm{H}_{\text {hydride, }} \mathrm{MHz}$ \\
\hline $\begin{array}{c}\text { pyramidal } \\
\text { model }\end{array}$ & $17^{\circ}$ & {$[-186,-283,-187]$} & {$[+39,+48,+52]$} \\
\hline $\begin{array}{c}\text { planar } \\
\text { model }\end{array}$ & $0^{\circ}$ & {$[-37,-144,-38]$} & {$[-41,-43,-58]_{\text {hydride }}$} \\
\hline exp. & $\approx 0^{\circ}$ & {$[-42,+43,+49]_{\beta}{ }^{1} \mathrm{H}_{\mathrm{H}}$} \\
\hline
\end{tabular}

C planar model

D SOMO of planar model
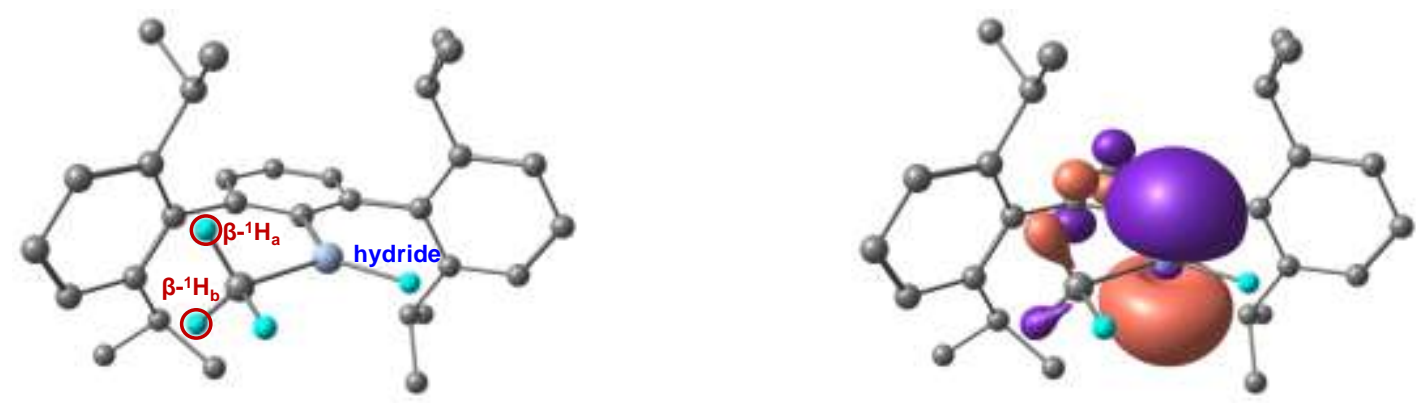

Figure S3. (A) The optimized geometry of $\mathrm{Ge}^{\mathrm{III}}$-hydride model with a methyl ligand to $\mathrm{Ge}^{\mathrm{III}}$ by presenting a pyramidal geometry for Ge center, with the out-plane-angle $\theta=17^{\circ}$ and the $\mathrm{Ge}-\mathrm{H}_{\text {hydride }}$ bond length $r=1.57 \AA$. (B) The DFT-predicted hyperfine-coupling values for Ge, the hydride and beta- ${ }^{1} \mathrm{H}$. (C) A trigonal-planar geometry of $\mathrm{Ge}^{\mathrm{III}}$-hydride model by constraining the dihedral angle between $\mathrm{H}-\mathrm{Ge}-\mathrm{C}_{\text {methyl }}$ and $\mathrm{H}-\mathrm{Ge}-\mathrm{C}_{\text {phenyl }}$ as $180^{\circ}$ on the above optimized pyramidal geometry shown in Figure A. (D) DFT calculated SOMO of the planar Ge $\mathrm{E}^{\mathrm{III}}$-hydride model shown in Figure C (isosurface value $=0.05$ a.u.).

The calculated hyperfine coupling constants of two beta- ${ }^{1} \mathrm{H}([+42,+49,+43] \mathrm{MHz}$ and $[+37,+39$, $+33] \mathrm{MHz}$ ) of the planar-germanium model are comparable in magnitude to that observed for the hydride ([-41, -43, -58] MHz), but with positive signs that originate from a spin-hyperconjunction mechanism. We did not detect any signals in the ENDOR experiment that would correspond to these calculated hyperfine values from beta- ${ }^{1} \mathrm{H}$. 


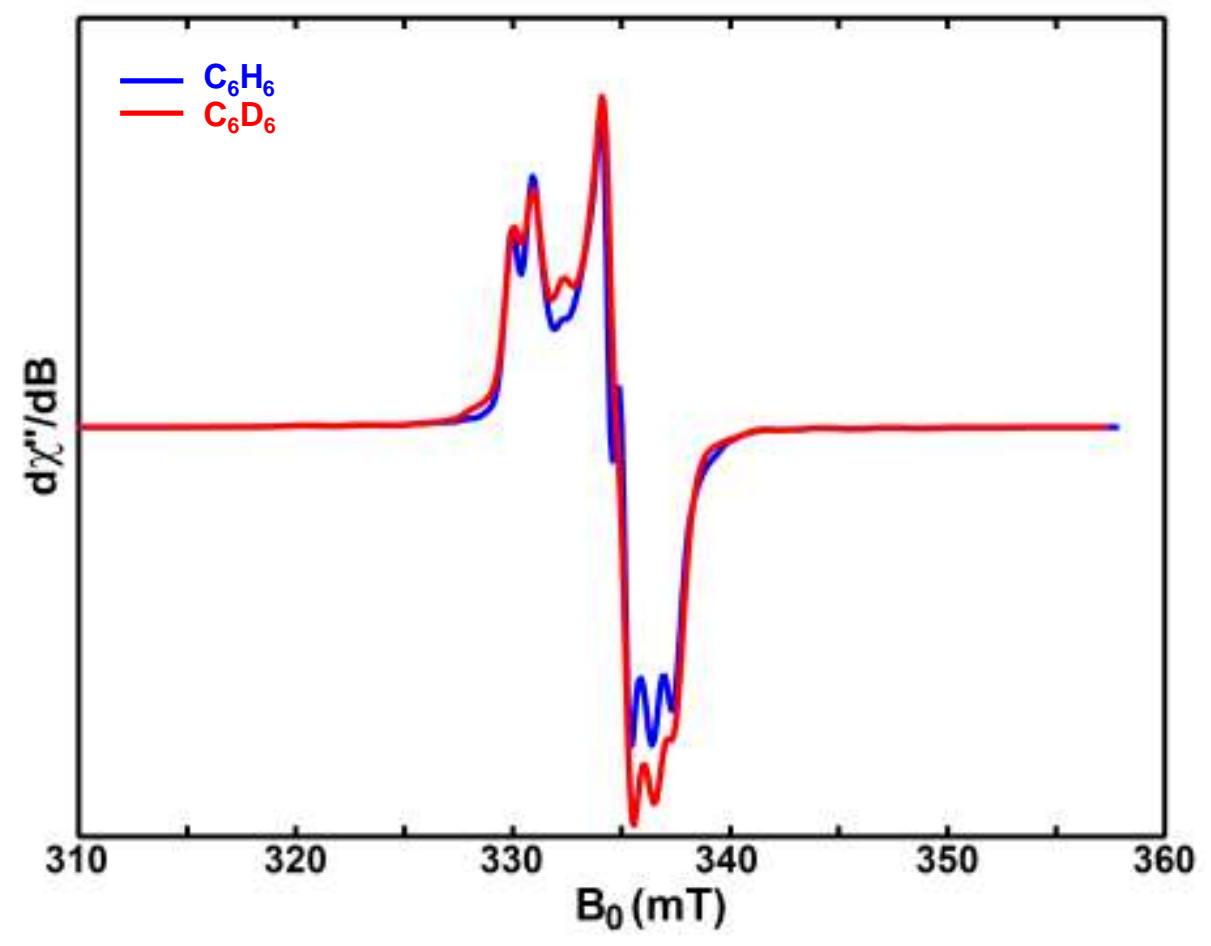

Figure S4. X-band (15 K) CW-EPR spectrum of the radical trapped by UV photolysis of $\mathrm{Ge}\left(\mathrm{Ar}^{\mathrm{iPr} 4}\right)_{2}$ in benzene (blue trace: $\mathrm{C}_{6} \mathrm{H}_{6}$; red trace: $\left.\mathrm{C}_{6} \mathrm{D}_{6}\right)$ for $\sim 30 \mathrm{~min}$. 
A pyramidal model

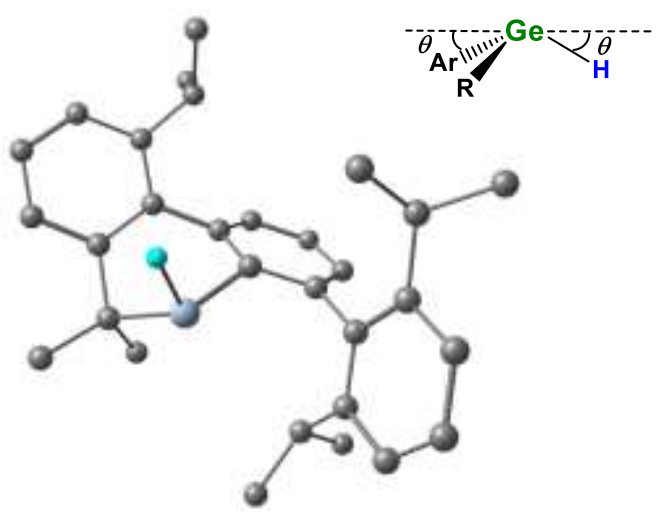

C

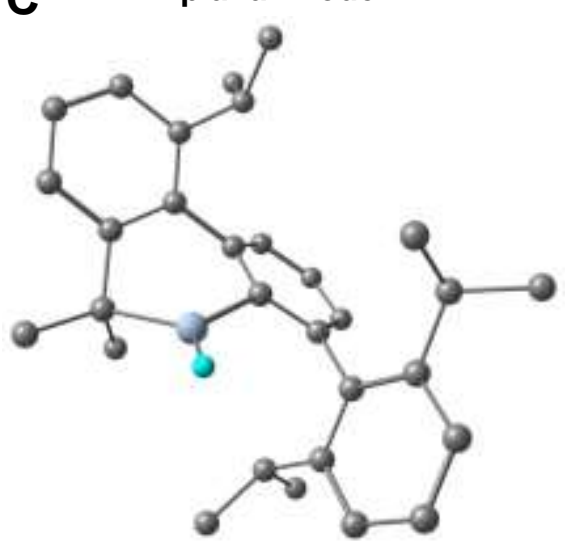

B

\begin{tabular}{|c|c|c|c|}
\hline & $\begin{array}{c}\text { out-of-plane } \\
\text { angle }(\theta)\end{array}$ & $A^{73} \mathrm{Ge}, \mathrm{MHz}$ & $A^{1} \mathrm{H}_{\text {hydride, }} \mathrm{MHz}$ \\
\hline $\begin{array}{c}\text { pyramidal } \\
\text { model }\end{array}$ & $22^{\circ}$ & {$[-214,-216,-306]$} & {$[+101,+108,+112]$} \\
\hline $\begin{array}{c}\text { planar } \\
\text { model }\end{array}$ & $0^{\circ}$ & {$[-46,-162,-49]$} & {$[-40,-43,-58]$} \\
\hline exp. & $\approx 0^{\circ}$ & {$[-10,-90,-10]$} & {$[-23.0,-20.5,-31.5]$} \\
\hline
\end{tabular}

D

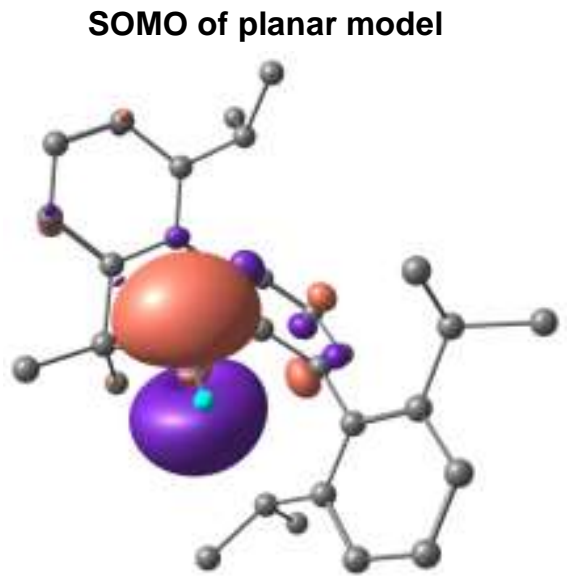

Figure S5. (A) The optimized geometry of the $\mathrm{Ge}^{\mathrm{III}}$-hydride radical model by presenting a pyramidal coordination for the germanium atom (no beta-proton in this model), with the out-planeangle $\theta=22^{\circ}$ and the Ge-H bond length $r=1.57 \AA$. (B) The DFT-predicted hyperfine coupling values for germanium and the hydride ${ }^{1} \mathrm{H}$. (C) A trigonal planar geometry of the Ge ${ }^{\mathrm{III}}$-hydride radical model by constraining the dihedral angle between $\mathrm{H}-\mathrm{Ge}-\mathrm{C}_{\text {isopropyl }}$ and $\mathrm{H}-\mathrm{Ge}-\mathrm{C}_{\text {phenyl }}$ as $180^{\circ}$ on the above optimized pyramidal geometry shown in Figure A. (D) DFT calculated SOMO of the planar the $\mathrm{Ge}^{\mathrm{III}}$-hydride radical model shown in Figure $\mathrm{C}$ (isosurface value $=0.05$ a.u.).

Yonezawa and coworkers ${ }^{28}$ employed theoretical calculations to study the relationship between the geometry of $\bullet \mathrm{CH}_{3}, \cdot \mathrm{SiH}_{3}$ and $\bullet \mathrm{GeH}_{3}$ radicals and the corresponding hyperfine coupling values of the hydrides. They suggested that these hyperfine-coupling values are very sensitive to the outplane-angle $\theta$ : as $\theta$ decreases, the spin-polarization contribution, which yields negative hyperfine coupling, becomes larger and is dominant in a planar geometry when $\theta=0^{\circ}$, as is approximately the case here for the $\mathrm{Ge}^{\mathrm{III}}$-hydride radical. 
Table S3. Cartesian coordinates of the optimized geometry of the Ge $\mathrm{Ge}^{\mathrm{III}}$-hydride radical model by presenting a pyramidal geometry for Ge center (shown in Figure S5A).

\begin{tabular}{lrcc}
\hline Atom & $\mathbf{x}$ & $\mathbf{y}$ & $\mathbf{z}$ \\
\hline $\mathrm{Ge}$ & 0.896286 & -1.483529 & 0.306499 \\
$\mathrm{H}$ & 2.352041 & -1.368852 & -0.286240 \\
$\mathrm{H}$ & -2.203062 & -5.481734 & -0.526697 \\
$\mathrm{H}$ & -3.373405 & -4.352445 & -2.441315 \\
$\mathrm{H}$ & -2.520858 & -2.181050 & -3.326677 \\
$\mathrm{H}$ & 2.467544 & -6.681698 & 1.718716 \\
$\mathrm{H}$ & 1.793196 & -5.978515 & 4.012978 \\
$\mathrm{H}$ & -0.066157 & -4.347232 & 4.331740 \\
$\mathrm{H}$ & 0.568170 & -5.679636 & -1.368563 \\
$\mathrm{H}$ & 2.239442 & -3.851946 & -1.192529 \\
$\mathrm{H}$ & 2.877045 & -5.177363 & -2.217200 \\
$\mathrm{H}$ & 3.455004 & -4.990676 & -0.525999 \\
$\mathrm{H}$ & 1.046228 & -7.988709 & -0.428219 \\
$\mathrm{H}$ & 2.772940 & -7.539255 & -0.249902 \\
$\mathrm{H}$ & 2.032300 & -7.581346 & -1.872279 \\
$\mathrm{H}$ & -1.751404 & -2.580738 & 1.458618 \\
$\mathrm{H}$ & -0.436812 & -1.557125 & 3.346143 \\
$\mathrm{H}$ & -1.324553 & -2.583444 & 4.520872 \\
$\mathrm{H}$ & -2.214022 & -1.379222 & 3.547980 \\
$\mathrm{H}$ & -3.127123 & -4.626756 & 1.794849 \\
$\mathrm{H}$ & -3.791913 & -3.254674 & 2.743322 \\
$\mathrm{H}$ & -2.852102 & -4.548456 & 3.564008 \\
$\mathrm{H}$ & 0.925486 & 2.303547 & -1.589968 \\
$\mathrm{H}$ & 1.312247 & 2.449924 & -4.036325 \\
$\mathrm{H}$ & 0.800140 & 0.494338 & -5.498723 \\
$\mathrm{H}$ & 0.391417 & 1.260040 & 1.728131 \\
$\mathrm{H}$ & 1.593877 & 1.525840 & 0.427676 \\
$\mathrm{H}$ & -1.704462 & -0.013479 & 1.368875 \\
$\mathrm{H}$ & -2.108716 & -0.739348 & -0.219973 \\
$\mathrm{H}$ & -2.150465 & 1.037962 & -0.014523 \\
$\mathrm{H}$ & -0.472335 & -2.801746 & -4.241527 \\
$\mathrm{H}$ & -2.183921 & -1.419064 & -5.463977 \\
$\mathrm{H}$ & -1.335187 & -2.556531 & -6.564473 \\
$\mathrm{H}$ & -0.913106 & -0.814941 & -6.568096 \\
$\mathrm{H}$ & 1.972726 & -2.532389 & -4.681173 \\
$\mathrm{H}$ & 1.616101 & -1.524841 & -6.120042 \\
$\mathrm{H}$ & 1.101593 & -3.239059 & -6.083351 \\
$\mathrm{C}$ & 0.017424 & 2.383379 & 0.389729 \\
& -0.253889 & -2.663036 & -0.790800 \\
& -0.730772 & -3.896533 & -0.294329 \\
& & & \\
\hline
\end{tabular}




\begin{tabular}{|c|c|c|c|}
\hline C & -2.484418 & -3.888616 & -1.9 \\
\hline C & -2.001754 & -2.669545 & -2.488501 \\
\hline & -0.863021 & -2.055335 & -1.920936 \\
\hline C & -0.059844 & -4.505981 & 0.898833 \\
\hline & 0.991185 & -5.444482 & 0.709830 \\
\hline 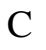 & 1.646661 & -5.960241 & 1.845291 \\
\hline & 1.269788 & -5.564840 & 3.136933 \\
\hline 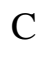 & 0.226645 & -4.645811 & 3.313969 \\
\hline & -0.451024 & -4.100559 & 2.205467 \\
\hline 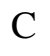 & 1.436539 & -5.839581 & -0.696168 \\
\hline C & 2.565737 & -4.910862 & -1.185850 \\
\hline 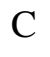 & 1.841595 & -7.317727 & -0.811873 \\
\hline C & -1.623211 & -3.144295 & 2.405608 \\
\hline $\mathrm{C}$ & -1.382370 & -2.112476 & 3.517660 \\
\hline C & -2.923588 & -3.938086 & 2.639305 \\
\hline C & -0.276519 & -0.804229 & -2.497216 \\
\hline C & 0.079371 & 0.300072 & -1.640333 \\
\hline $\mathrm{C}$ & 0.658183 & 1.448847 & -2.224039 \\
\hline $\mathrm{C}$ & 0.881188 & 1.533725 & -3.604053 \\
\hline $\mathrm{C}$ & 0.578869 & 0.441807 & -4.421646 \\
\hline 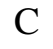 & 0.024431 & -0.742356 & -3.888448 \\
\hline $\mathrm{C}$ & -0.123723 & 0.251088 & -0.129169 \\
\hline 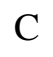 & 0.510545 & 1.417275 & 0.637349 \\
\hline 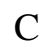 & -1.603595 & 0.113151 & 0.272150 \\
\hline 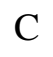 & -0.136078 & -1.931967 & -4.836548 \\
\hline 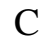 & -1.201444 & -1.666139 & -5.915806 \\
\hline & 1.215402 & -2.325293 & -5.464113 \\
\hline
\end{tabular}


Table S4. Cartesian coordinates of the geometry of the Ge $\mathrm{e}^{\mathrm{III}}$-hydride radical model by presenting a planar geometry for Ge center (shown in Figure 4\&S5C).

\begin{tabular}{lrcc}
\hline Atom & $\mathbf{x}$ & $\mathbf{y}$ & $\mathbf{z}$ \\
\hline $\mathrm{Ge}$ & 0.896000 & -1.484000 & 0.306000 \\
$\mathrm{H}$ & 2.158000 & -1.779000 & 1.203000 \\
$\mathrm{H}$ & -2.203000 & -5.482000 & -0.527000 \\
$\mathrm{H}$ & -3.373000 & -4.352000 & -2.441000 \\
$\mathrm{H}$ & -2.521000 & -2.181000 & -3.327000 \\
$\mathrm{H}$ & 2.468000 & -6.682000 & 1.719000 \\
$\mathrm{H}$ & 1.793000 & -5.979000 & 4.013000 \\
$\mathrm{H}$ & -0.066000 & -4.347000 & 4.332000 \\
$\mathrm{H}$ & 0.568000 & -5.680000 & -1.369000 \\
$\mathrm{H}$ & 2.239000 & -3.852000 & -1.193000 \\
$\mathrm{H}$ & 2.877000 & -5.177000 & -2.217000 \\
$\mathrm{H}$ & 3.455000 & -4.991000 & -0.526000 \\
$\mathrm{H}$ & 1.046000 & -7.989000 & -0.428000 \\
$\mathrm{H}$ & 2.773000 & -7.539000 & -0.250000 \\
$\mathrm{H}$ & 2.032000 & -7.581000 & -1.872000 \\
$\mathrm{H}$ & -1.751000 & -2.581000 & 1.459000 \\
$\mathrm{H}$ & -0.437000 & -1.557000 & 3.346000 \\
$\mathrm{H}$ & -1.325000 & -2.583000 & 4.521000 \\
$\mathrm{H}$ & -2.214000 & -1.379000 & 3.548000 \\
$\mathrm{H}$ & -3.127000 & -4.627000 & 1.795000 \\
$\mathrm{H}$ & -3.792000 & -3.255000 & 2.743000 \\
$\mathrm{H}$ & -2.852000 & -4.548000 & 3.564000 \\
$\mathrm{H}$ & 0.925000 & 2.304000 & -1.590000 \\
$\mathrm{H}$ & 1.312000 & 2.450000 & -4.036000 \\
$\mathrm{H}$ & 0.800000 & 0.494000 & -5.499000 \\
$\mathrm{H}$ & 0.391000 & 1.260000 & 1.728000 \\
$\mathrm{H}$ & 1.594000 & 1.526000 & 0.428000 \\
$\mathrm{H}$ & 0.017000 & 2.383000 & 0.390000 \\
$\mathrm{H}$ & -1.704000 & -0.013000 & 1.369000 \\
$\mathrm{H}$ & -2.109000 & -0.739000 & -0.220000 \\
$\mathrm{H}$ & -2.150000 & 1.038000 & -0.015000 \\
$\mathrm{H}$ & -0.472000 & -2.802000 & -4.242000 \\
$\mathrm{H}$ & -2.184000 & -1.419000 & -5.464000 \\
$\mathrm{H}$ & -1.335000 & -2.557000 & -6.564000 \\
$\mathrm{H}$ & -0.913000 & -0.815000 & -6.568000 \\
$\mathrm{H}$ & 1.973000 & -2.532000 & -4.681000 \\
$\mathrm{H}$ & 1.616000 & -1.525000 & -6.120000 \\
$\mathrm{C}$ & 1.102000 & -3.239000 & -6.083000 \\
& -0.254000 & -2.663000 & -0.791000 \\
& -1.731000 & -3.897000 & -0.294000 \\
& & &
\end{tabular}




\begin{tabular}{|c|c|c|c|}
\hline C & -2.484000 & -3.889000 & 7000 \\
\hline C & -2.002000 & -2.670000 & -2.489000 \\
\hline & -0.863000 & -2.055000 & -1.921000 \\
\hline C & -0.060000 & -4.506000 & 0.899000 \\
\hline & 0.991000 & -5.444000 & 0.710000 \\
\hline 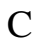 & 1.647000 & -5.960000 & 1.845000 \\
\hline & 1.270000 & -5.565000 & 3.137000 \\
\hline 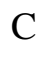 & 0.227000 & -4.646000 & 3.314000 \\
\hline & -0.451000 & -4.101000 & 2.205000 \\
\hline 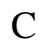 & 1.437000 & -5.840000 & -0.696000 \\
\hline & 2.566000 & -4.911000 & -1.186000 \\
\hline 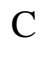 & 1.842000 & -7.318000 & -0.812000 \\
\hline C & -1.623000 & -3.144000 & 2.406000 \\
\hline $\mathrm{C}$ & -1.382000 & -2.112000 & 3.518000 \\
\hline$C$ & -2.924000 & -3.938000 & 2.639000 \\
\hline 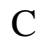 & -0.277000 & -0.804000 & -2.497000 \\
\hline C & 0.079000 & 0.300000 & -1.640000 \\
\hline C & 0.658000 & 1.449000 & -2.224000 \\
\hline $\mathrm{C}$ & 0.881000 & 1.534000 & -3.604000 \\
\hline $\mathrm{C}$ & 0.579000 & 0.442000 & -4.422000 \\
\hline 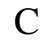 & 0.024000 & -0.742000 & -3.888000 \\
\hline $\mathrm{C}$ & -0.124000 & 0.251000 & -0.129000 \\
\hline 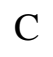 & 0.511000 & 1.417000 & 0.637000 \\
\hline 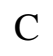 & -1.604000 & 0.113000 & 0.272000 \\
\hline 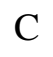 & -0.136000 & -1.932000 & -4.837000 \\
\hline & -1.201000 & -1.666000 & -5.916000 \\
\hline & 1.215000 & -2.325000 & -5.464000 \\
\hline
\end{tabular}


Table S5. Cartesian coordinates of the optimized geometry of the Ge $\mathrm{e}^{\mathrm{III}}$-hydride radical model by presenting a pyramidal geometry for Ge center (shown in Figure S3A).

\begin{tabular}{lrrr}
\hline Atom & \multicolumn{1}{c}{$\mathbf{x}$} & $\mathbf{y}$ & $\mathbf{z}$ \\
\hline $\mathrm{Ge}$ & 1.580544 & 0.789507 & 0.725189 \\
$\mathrm{H}$ & 2.283364 & 1.630708 & -0.373278 \\
$\mathrm{H}$ & -2.222882 & -2.676975 & 0.488049 \\
$\mathrm{H}$ & -3.412945 & -1.531565 & -1.404544 \\
$\mathrm{H}$ & -2.444400 & 0.573350 & -2.385057 \\
$\mathrm{H}$ & 2.167943 & -4.596293 & 2.357839 \\
$\mathrm{H}$ & 1.958939 & -3.662081 & 4.655514 \\
$\mathrm{H}$ & 0.524026 & -1.664486 & 5.075946 \\
$\mathrm{H}$ & 0.021987 & -3.512959 & -0.474821 \\
$\mathrm{H}$ & 1.813935 & -1.846161 & -0.884658 \\
$\mathrm{H}$ & 2.103470 & -3.332023 & -1.839670 \\
$\mathrm{H}$ & 3.062662 & -3.024945 & -0.354616 \\
$\mathrm{H}$ & 0.537007 & -5.752804 & 0.611757 \\
$\mathrm{H}$ & 2.286367 & -5.439615 & 0.369078 \\
$\mathrm{H}$ & 1.206518 & -5.573982 & -1.044279 \\
$\mathrm{H}$ & -1.171606 & 0.260710 & 2.293760 \\
$\mathrm{H}$ & 0.665093 & 1.174483 & 3.734293 \\
$\mathrm{H}$ & -0.101721 & 0.450211 & 5.188386 \\
$\mathrm{H}$ & -0.957567 & 1.720230 & 4.265003 \\
$\mathrm{H}$ & -2.805110 & -1.411215 & 3.149418 \\
$\mathrm{H}$ & -2.993776 & 0.158762 & 4.001617 \\
$\mathrm{H}$ & -2.169126 & -1.214909 & 4.813696 \\
$\mathrm{H}$ & -0.247021 & 5.248751 & -1.007003 \\
$\mathrm{H}$ & 1.241230 & 5.232286 & -3.009100 \\
$\mathrm{H}$ & 1.827371 & 3.076123 & -4.121553 \\
$\mathrm{H}$ & -1.580931 & 2.066723 & 0.572665 \\
$\mathrm{H}$ & -1.555462 & 3.842369 & 2.290887 \\
$\mathrm{H}$ & 0.109849 & 3.517950 & 1.704040 \\
$\mathrm{H}$ & -0.768504 & 4.990340 & 1.167404 \\
$\mathrm{H}$ & -3.556314 & 3.594430 & 0.686082 \\
$\mathrm{H}$ & -3.288100 & 2.991948 & -0.984710 \\
$\mathrm{H}$ & -2.814059 & 4.664528 & -0.550051 \\
$\mathrm{H}$ & 0.631844 & -0.282025 & -2.799657 \\
$\mathrm{H}$ & -0.706273 & 0.500545 & -4.756189 \\
$\mathrm{H}$ & 0.642140 & -0.561245 & -5.285943 \\
$\mathrm{H}$ & 0.758740 & 1.216149 & -5.498811 \\
$\mathrm{H}$ & 3.015425 & 0.419834 & -2.471846 \\
& 3.055833 & 1.101527 & -4.129151 \\
& 2.818690 & -0.657908 & -3.895334 \\
& & & \\
$\mathrm{H}$ & & \\
$\mathrm{H}$ & & &
\end{tabular}




\begin{tabular}{lrrr}
$\mathrm{H}$ & 3.794030 & 0.331858 & 1.882021 \\
$\mathrm{C}$ & 2.928008 & -0.317726 & 1.648137 \\
$\mathrm{C}$ & -0.022803 & -0.076900 & -0.020817 \\
$\mathrm{C}$ & -0.587894 & -1.255876 & 0.542463 \\
$\mathrm{C}$ & -1.800206 & -1.765851 & 0.036515 \\
$\mathrm{C}$ & -2.466028 & -1.124169 & -1.018787 \\
$\mathrm{C}$ & -1.926455 & 0.050048 & -1.566582 \\
$\mathrm{C}$ & -0.724333 & 0.586601 & -1.068716 \\
$\mathrm{C}$ & 0.087111 & -1.950637 & 1.681163 \\
$\mathrm{C}$ & 0.873258 & -3.111725 & 1.436903 \\
$\mathrm{C}$ & 1.543879 & -3.706254 & 2.523117 \\
$\mathrm{C}$ & 1.426360 & -3.182453 & 3.819618 \\
$\mathrm{C}$ & 0.624320 & -2.057648 & 4.052826 \\
$\mathrm{C}$ & -0.053498 & -1.423010 & 2.992332 \\
$\mathrm{C}$ & 0.999662 & -3.682105 & 0.022835 \\
$\mathrm{C}$ & 2.054614 & -2.924850 & -0.808828 \\
$\mathrm{C}$ & 1.270335 & -5.193955 & -0.004443 \\
$\mathrm{C}$ & -0.959064 & -0.224870 & 3.267694 \\
$\mathrm{C}$ & -0.298973 & 0.833314 & 4.165572 \\
$\mathrm{C}$ & -2.308993 & -0.699666 & 3.840095 \\
$\mathrm{C}$ & -0.199364 & 1.872045 & -1.626025 \\
$\mathrm{C}$ & -0.528474 & 3.091987 & -0.978119 \\
$\mathrm{C}$ & -0.000524 & 4.292448 & -1.493718 \\
$\mathrm{C}$ & 0.836502 & 4.285491 & -2.618757 \\
$\mathrm{C}$ & 1.162016 & 3.073103 & -3.244000 \\
$\mathrm{C}$ & 0.658434 & 1.851469 & -2.755897 \\
$\mathrm{C}$ & -1.461688 & 3.114916 & 0.229695 \\
$\mathrm{C}$ & -0.884722 & 3.913459 & 1.409927 \\
$\mathrm{C}$ & -2.859284 & 3.619520 & -0.177372 \\
$\mathrm{C}$ & 1.042689 & 0.535980 & -3.426155 \\
$\mathrm{C}$ & 0.397650 & 0.415654 & -4.819178 \\
$\mathrm{C}$ & 2.568132 & 0.341465 & -3.483526 \\
\hline & & & \\
\hline
\end{tabular}


Table S6. Cartesian coordinates of the geometry of the Ge $\mathrm{e}^{\mathrm{III}}$-hydride radical model by presenting a planar geometry for Ge center (shown in Figure S3C).

\begin{tabular}{lrrc}
\hline Atom & \multicolumn{1}{c}{$\mathbf{x}$} & $\mathbf{y}$ & $\mathbf{z}$ \\
\hline $\mathrm{Ge}$ & 1.672000 & 0.649000 & 0.671000 \\
$\mathrm{H}$ & 2.509000 & 1.891000 & 0.265000 \\
$\mathrm{H}$ & 1.983000 & -0.233000 & 3.088000 \\
$\mathrm{H}$ & 2.739000 & -1.342000 & 1.891000 \\
$\mathrm{H}$ & 3.558000 & 0.212000 & 2.314000 \\
$\mathrm{H}$ & -2.223000 & -2.677000 & 0.488000 \\
$\mathrm{H}$ & -3.413000 & -1.532000 & -1.405000 \\
$\mathrm{H}$ & -2.444000 & 0.573000 & -2.385000 \\
$\mathrm{H}$ & 2.168000 & -4.596000 & 2.358000 \\
$\mathrm{H}$ & 1.959000 & -3.662000 & 4.656000 \\
$\mathrm{H}$ & 0.524000 & -1.664000 & 5.076000 \\
$\mathrm{H}$ & 0.022000 & -3.513000 & -0.475000 \\
$\mathrm{H}$ & 1.814000 & -1.846000 & -0.885000 \\
$\mathrm{H}$ & 2.103000 & -3.332000 & -1.840000 \\
$\mathrm{H}$ & 3.063000 & -3.025000 & -0.355000 \\
$\mathrm{H}$ & 0.537000 & -5.753000 & 0.612000 \\
$\mathrm{H}$ & 2.286000 & -5.440000 & 0.369000 \\
$\mathrm{H}$ & 1.207000 & -5.574000 & -1.044000 \\
$\mathrm{H}$ & -1.172000 & 0.261000 & 2.294000 \\
$\mathrm{H}$ & 0.665000 & 1.174000 & 3.734000 \\
$\mathrm{H}$ & -0.102000 & 0.450000 & 5.188000 \\
$\mathrm{H}$ & -0.958000 & 1.720000 & 4.265000 \\
$\mathrm{H}$ & -2.805000 & -1.411000 & 3.149000 \\
$\mathrm{H}$ & -2.994000 & 0.159000 & 4.002000 \\
$\mathrm{H}$ & -2.169000 & -1.215000 & 4.814000 \\
$\mathrm{H}$ & -0.247000 & 5.249000 & -1.007000 \\
$\mathrm{H}$ & 1.241000 & 5.232000 & -3.009000 \\
$\mathrm{H}$ & 1.827000 & 3.076000 & -4.122000 \\
$\mathrm{H}$ & -1.581000 & 2.067000 & 0.573000 \\
$\mathrm{H}$ & -1.555000 & 3.842000 & 2.291000 \\
$\mathrm{H}$ & 0.110000 & 3.518000 & 1.704000 \\
$\mathrm{H}$ & -0.769000 & 4.990000 & 1.167000 \\
$\mathrm{H}$ & -3.556000 & 3.594000 & 0.686000 \\
$\mathrm{H}$ & -3.288000 & 2.992000 & -0.985000 \\
$\mathrm{H}$ & -2.814000 & 4.665000 & -0.550000 \\
$\mathrm{H}$ & 0.632000 & -0.282000 & -2.800000 \\
$\mathrm{H}$ & -0.706000 & 0.501000 & -4.756000 \\
& 0.642000 & -0.561000 & -5.286000 \\
& 3.759000 & 1.216000 & -5.499000 \\
& 3.056000 & 1.102000 & -4.129000
\end{tabular}




\begin{tabular}{lrrr}
$\mathrm{H}$ & 2.819000 & -0.658000 & -3.895000 \\
$\mathrm{C}$ & 2.578000 & -0.279000 & 2.158000 \\
$\mathrm{C}$ & -0.023000 & -0.077000 & -0.021000 \\
$\mathrm{C}$ & -0.588000 & -1.256000 & 0.542000 \\
$\mathrm{C}$ & -1.800000 & -1.766000 & 0.037000 \\
$\mathrm{C}$ & -2.466000 & -1.124000 & -1.019000 \\
$\mathrm{C}$ & -1.926000 & 0.050000 & -1.567000 \\
$\mathrm{C}$ & -0.724000 & 0.587000 & -1.069000 \\
$\mathrm{C}$ & 0.087000 & -1.951000 & 1.681000 \\
$\mathrm{C}$ & 0.873000 & -3.112000 & 1.437000 \\
$\mathrm{C}$ & 1.544000 & -3.706000 & 2.523000 \\
$\mathrm{C}$ & 1.426000 & -3.182000 & 3.820000 \\
$\mathrm{C}$ & 0.624000 & -2.058000 & 4.053000 \\
$\mathrm{C}$ & -0.053000 & -1.423000 & 2.992000 \\
$\mathrm{C}$ & 1.000000 & -3.682000 & 0.023000 \\
$\mathrm{C}$ & 2.055000 & -2.925000 & -0.809000 \\
$\mathrm{C}$ & 1.270000 & -5.194000 & -0.004000 \\
$\mathrm{C}$ & -0.959000 & -0.225000 & 3.268000 \\
$\mathrm{C}$ & -0.299000 & 0.833000 & 4.166000 \\
$\mathrm{C}$ & -2.309000 & -0.700000 & 3.840000 \\
$\mathrm{C}$ & -0.199000 & 1.872000 & -1.626000 \\
$\mathrm{C}$ & -0.528000 & 3.092000 & -0.978000 \\
$\mathrm{C}$ & -0.001000 & 4.292000 & -1.494000 \\
$\mathrm{C}$ & 0.837000 & 4.285000 & -2.619000 \\
$\mathrm{C}$ & 1.162000 & 3.073000 & -3.244000 \\
$\mathrm{C}$ & 0.658000 & 1.851000 & -2.756000 \\
$\mathrm{C}$ & -1.462000 & 3.115000 & 0.230000 \\
$\mathrm{C}$ & -0.885000 & 3.913000 & 1.410000 \\
$\mathrm{C}$ & -2.859000 & 3.620000 & -0.177000 \\
$\mathrm{C}$ & 1.043000 & 0.536000 & -3.426000 \\
$\mathrm{C}$ & 0.398000 & 0.416000 & -4.819000 \\
$\mathrm{C}$ & 2.568000 & 0.341000 & -3.484000 \\
\hline & & & \\
\hline
\end{tabular}




\section{References}

1. Simons, R. S.; Pu, L.; Olmstead, M. M.; Power, P. P., Synthesis and characterization of the monomeric diaryls $\mathrm{M}\left\{\mathrm{C}_{6} \mathrm{H}_{3}-2,6-\mathrm{Mes}_{2}\right\}_{2}\left(\mathrm{M}=\mathrm{Ge}, \mathrm{Sn}\right.$, or $\mathrm{Pb}$; Mes = 2,4,6- $\left.\mathrm{Me}_{3} \mathrm{C}_{6} \mathrm{H}_{2}-\right)$ and dimeric aryl-metal chlorides $\left[\mathrm{M}(\mathrm{Cl})\left\{\mathrm{C}_{6} \mathrm{H}_{3}-2,6-\mathrm{Mes}_{2}\right\}\right]_{2}(\mathrm{M}=\mathrm{Ge}$ or Sn). Organometallics 1997, $16(9), 1920-1925$. 2. Stoll, S.; Britt, R. D., General and efficient simulation of pulse EPR spectra. Phy. Chem. Chem. Phy. 2009, 11 (31), 6614-6625.

3. Stoll, S.; Schweiger, A., EasySpin, a comprehensive software package for spectral simulation and analysis in EPR. J. Magn. Reson. 2006, 178 (1), 42-55.

4. $\quad$ Davies, E. R., A new pulse endor technique. Physics Letters A 1974, 47 (1), 1-2.

5. $\quad$ Bruggemann, W.; Niklas, J. R., Stochastic ENDOR. J. Magn. Reson 1994, 108 (1), 25-29.

6. Epel, B.; Manikandan, P.; Kroneck, P. M. H.; Goldfarb, D., High-field ENDOR and the sign of the hyperfine coupling. Appl. Magn. Reson. 2001, 21 (3), 287-297.

7. Neese, F., ORCA-an ab initio, Density Functional and Semiempirical Program Package. University of Bonn: Bonn, Germany, 2007; Vol. v. 2.6-35.

8. Perdew, J. P., Density-functional approximation for the correlation energy of the inhomogeneous electron gas. Phys. Rev. B 1986, 33 (12), 8822-8824.

9. Becke, A. D., Density-functional exchange-energy approximation with correct asymptotic behavior. Phys. Rev. A 1988, 38 (6), 3098-3100.

10. van Lenthe, E.; Ehlers, A.; Baerends, E.-J., Geometry optimizations in the zero order regular approximation for relativistic effects. J. Chem. Phys. 1999, 110 (18), 8943-8953.

11. Lenthe, E. v.; Baerends, E. J.; Snijders, J. G., Relativistic regular two-component Hamiltonians. $J$. Chem. Phys. 1993, 99 (6), 4597-4610.

12. Wüllen, C. v., Molecular density functional calculations in the regular relativistic approximation: method, application to coinage metal diatomics, hydrides, fluorides and chlorides, and comparison with first-order relativistic calculations. J. Chem. Phys. 1998, 109 (2), 392-399.

13. Pantazis, D. A.; Chen, X.-Y.; Landis, C. R.; Neese, F., All-electron scalar relativistic basis sets for third-row transition metal atoms. J. Chem. Theory Comput. 2008, 4 (6), 908-919.

14. Pantazis, D. A.; Neese, F., All-electron scalar relativistic basis sets for the $6 \mathrm{p}$ elements. Theor. Chem. Acc. 2012, 131 (11), 1292.

15. Klamt, A.; Schuurmann, G., COSMO: a new approach to dielectric screening in solvents with explicit expressions for the screening energy and its gradient. J. Chem. Soc., Perkin Trans. 2. 1993, (5), 799-805.

16. Blachly, P. G.; Sandala, G. M.; Giammona, D. A.; Bashford, D.; McCammon, J. A.; Noodleman, L., Broken-symmetry DFT computations for the reaction pathway of IspH, an iron-sulfur enzyme in pathogenic bacteria. Inorg. Chem. 2015, 54 (13), 6439-6461.

17. Blachly, P. G.; Sandala, G. M.; Giammona, D. A.; Liu, T.; Bashford, D.; McCammon, J. A.; Noodleman, L., Use of broken-symmetry density functional theory to characterize the IspH oxidized state: implications for IspH mechanism and inhibition. J. Chem. Theory Comput. 2014, 10 (9), 3871-3884.

18. Staroverov, V. N.; Scuseria, G. E.; Tao, J.; Perdew, J. P., Comparative assessment of a new nonempirical density functional: Molecules and hydrogen-bonded complexes. J. Chem. Phys. 2003, 119 (23), 12129-12137.

19. Morehouse, R. L.; Christiansen, J. J.; Gordy, W., ESR of free radicals trapped in inert matrices at low temperature: $\mathrm{CH}_{3}, \mathrm{SiH}_{3}, \mathrm{GeH}_{3}$, and $\mathrm{SnH}_{3}$. J. Chem. Phys. 1966, 45 (5), 1751-1758.

20. Jackel, G. S.; Gordy, W., Electron spin resonance of free radicals formed from Group-IV and Group-V hydrides in inert matrices at low temperature. Phys. Rev. 1968, 176 (2), 443-452.

21. Bennett, S. W.; Eaborn, C.; Hudson, A.; Hussain, H. A.; Jackson, R. A., Electron spin resonance spectra of trimethylsilyl, trimethylgermyl and related free radicals in solution. J. Organomet.Chem. 1969, 16 (2), P36-P38.

22. Geoffroy, M.; Ginet, L.; Lucken, E. A. C., ESR study of the triphenylgermyl radical in a single crystal of triphenylgermane. Chem. Phys. Lett. 1976, 38 (2), 321-324. 
23. Cotton, J. D.; Cundy, C. S.; Harris, D. H.; Hudson, A.; Lappert, M. F.; Lednor, P. W., Photochemical synthesis and electron spin resonance characterisation of stable trivalent metal alkyls ( $\mathrm{Si}$, $\mathrm{Ge}, \mathrm{Sn}$ ) and amides (Ge and Sn) of Group IV elements. J. Chem. Soc., Chem. Commun. 1974, (16), 651652.

24. Sekiguchi, A.; Fukawa, T.; Nakamoto, M.; Lee, V. Y.; Ichinohe, M., Isolable silyl and germyl radicals lacking conjugation with $\pi$-bonds: synthesis, characterization, and reactivity. J. Am. Chem. Soc. 2002, 124 (33), 9865-9869.

25. Egorov, M. P.; Nefedov, O. M.; Lin, T.-S.; Gaspar, P. P., Germylene and stannylene anion-radicals: generation and electronic structure. Organometallics 1995, 14 (3), 1539-1541.

26. Siddiqui, M. M.; Sarkar, S. K.; Sinhababu, S.; Ruth, P. N.; Herbst-Irmer, R.; Stalke, D.; Ghosh, M.; Fu, M.; Zhao, L.; Casanova, D.; Frenking, G.; Schwederski, B.; Kaim, W.; Roesky, H. W., Isolation of transient acyclic germanium(I) radicals stabilized by cyclic alkyl(amino) carbenes. J. Am. Chem. Soc. 2019, 141 (5), 1908-1912.

27. Woodul, W. D.; Carter, E.; Müller, R.; Richards, A. F.; Stasch, A.; Kaupp, M.; Murphy, D. M.; Driess, M.; Jones, C., A neutral, monomeric germanium(I) radical. J. Am. Chem. Soc. 2011, 133 (26), 10074-10077.

28. Ohta, K.; Nakatsuji, H.; Maeda, I.; Yonezawa, T., Ab initio calculation of geometries and hfs constants of $\mathrm{CH}_{3}, \mathrm{SiH}_{3}$ and $\mathrm{GeH}_{3}$ radicals. Chem. Phys. 1982, 67 (1), 49-58. 